\title{
BANKIM'S RAJANI: A STUDY INTO HEALTH AND HUMANITY
}

\author{
Dr. P. Dalai ${ }^{*}{ }^{\square}$, Dr. Dhriti Ray Dalai ${ }^{2}$ \\ ${ }^{* 1,2}$ Associate Professor, Department of English, Faculty of Arts, Banaras Hindu University, \\ Varanasi, 221005, India
}

DOI: https://doi.org/10.29121/granthaalayah.v8.i6.2020.621

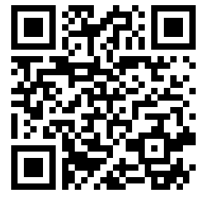

Article Type: Case Study

Article Citation: Dr. P. Dalai, and Dr. Dhriti Ray Dalai. (2020).

BANKIM'S RAJANI: A STUDY INTO

HEALTH AND HUMANITY.

International Journal of Research GRANTHAALAYAH, 8(6), 293-298.

https://doi.org/10.29121/granthaa

layah.v8.i6.2020.621

Received Date: 03 May 2020

Accepted Date: 28 June 2020

Keywords:

Blindness

Disability

Infirmity

Impairment

Human Health

Medical Humanities

\begin{abstract}
Though there has been a plethora of books and articles written on Bankim Chandra Chattopadhyay's eponymous fiction Rajani, what is conspicuous after all these is the necessity of a medical humanities' perspective into this masterpiece of Chattopadhyay. To fulfill such lacuna in the previous studies, the present article makes a hermeneutical attempt to contextualize Rajani at the backdrop of medical knowledge and medical culture during Colonial India. With this hypothesis, the paper proves how Bankim stirs the public imaginations about human health, hygiene and disability along with their cultural and clinical manifestations and ramifications, especially in colonial Bengal.
\end{abstract}

\section{INTRODUCTION}

Health as an epistemic discourse has been part of India's creative and critical praxis. Though not entirely clinical, but in its literary and cultural manifestations health has often stirred public imaginations in India about human body, sickness, disease, deformities, including their causes and cures. We tend to discern a historical progression of such health discourses from its mythological incarnations in the great Indian epics and scriptures till the introduction of English education and the subsequent rise of western knowledge/clinical ideas concerning health and humanities.

Hardly a half century after the introduction of Macaulay's Minute on English education in 1835, Bankim Chandra Chattopadhyay etches out a brilliant literary testimony to the emerging health concerns in India, particularly in the colonial Bengal in 1881. Chattopadhyay's Rajani (published in Bengali year 1287, English year 1881) documenting a cultural perspective into blindness ensues further creative discourses on health, hygiene, disability and their subsequent cultural manifestations and constructions. Chattopadhyay orchestrates both cultural and clinical resonances of oriental health consciousness through the blind heroine Rajani. At least, this is what the postmodern readers have to realize, particularly at the backdrop of contemporary emphasis on health studies and health humanities. Though there has been a plethora of books and articles written on Rajani, what is conspicuous after all

(C) 2020 The Author(s). This is an open access article distributed under the terms of the Creative Commons Attribution License, which permits unrestricted use, distribution, and reproduction in any medium, provided the original author and source are credited. 
these is the necessity of a medical humanities' perspective into this masterpiece of Bankim Chandra Chattopadhyay. To fulfill such lacuna in the previous studies, the present article makes a hermeneutical attempt to contextualize Rajani at the backdrop of medical knowledge and medical culture in Colonial India.

The paper is an effort to revisit the Bengal Renaissance through Bankim Chandra Chattopadhyay's eponymous heroine Rajani, living a life intersected with various axes of differentiation - impairment arising out of congenital blindness, gender and class. Rajani like, there would have been many individual cases of 'infirmities', but these lives were lived on the margin, with limited access to the basic parameters of health. Their survival presupposed a physical, mental and social marginalization. Bankim through Rajani (1881) not only provides to posterity one of the earliest person with disability or PWD narratives in the vernacular, but also inadvertently chronicles the ramifications of being a poor visually impaired girl in the late nineteenth century colonial Bengal, and the limitations to health that came consequently. In the course of this article, we also draw attention to the politics of health that operated at that point of time that demarcated the differences between the conflicting cultures, civilizations and races. With the main thrust of colonial medical consideration reserved for the whites, and the public health concerns primarily focused on epidemics, there were minimal or negligent awareness about the 'infirm' and their sociocultural limitations.

\section{INTERPRETATION}

Firmly located within the phase of history known as the Bengal Renaissance the novel is often read as a romantic tale involving Rajani, a blind but beautiful girl, and two men Sacindra and Amarnath. Rajani, coming from a poor background, falls in love with Sacindra babu when she visits their house to sell garlands. Lalitalabangalata, Sacindra babu's stepmother, unknowingly arranges Rajani's marriage with an already married Gopal, whose wife could not provide him with an heir. Gopal is moreover lured by the promise of a good amount of money if he agrees to marry Rajani. In the meantime, Gopal's wife, feeling aggrieved at the prospect of the second marriage, sends her brother Hiralal to take Rajani away on the night before the wedding to their parent's house. On their way Hiralal attempts to force Rajani into agreeing to marry him, which when she resists is deserted on the banks of the river Hooghly. Somehow, Rajani is rescued by Amarnath, the onetime suitor of Lalitalabangalata, and who later on proves instrumental in revealing Rajani's true parentage and bringing her a substantial inheritance. With Rajani coming to money she suddenly becomes a viable candidate for marriage with Sacindra, who though, still has reservations about it because of her blindness. By a strange dispensation of providence, an ascetic cures Rajani of her blindness, and Rajani and Sacindra are finally united in holy matrimony.

In the prefatory introduction though, Bankim acknowledges his intellectual debt to Edward George Earle Bulwer Lytton's The Last Days of Pompeii (1834), as it furnished him with the model of the character of Rajani in Nydia, a blind flower girl. Bankim, in the capacity of a deputy Magistrate and deputy Collector in the services of British India, may have had access to many western thoughts and practices and thus could narrate the experiences of a blind girl with so much conviction in Rajani. Victorian England had already been exposed to the sufferings of a blind Tiny Tim and Edward Rochester, occupying the two opposite spectrums of economics, poverty and prosperity respectively. More than Rochester, it was Tiny Tim from Dickens' A Christmas Carol (1843) that Victorian society gathered the knowledge of the 'impaired' as a burden on the family, the society and the economy. Is Rajani similarly providing Bankim the impetus to narrate an analogous tale of suffering, deprivation, disempowerment and exploitation of a visually impaired in the Indian context, where blindness was said to be more prevalent than in Europe or North America? "The colonial census estimated the average prevalence of blindness at 14/10000 compared to 8/10000 in Europe and North America" (qtd in Nair, 2017, p. 186).

Bengal's leading literary personality before Tagore, Bankim Chandra Chattopadhyay (1838-1894) was long acknowledged as possessing liberal, cosmopolitan values. He was one who prolifically wrote on popular science, agriculture, Bengali history and contemporary social issues. If the 1879 essay "Samya" (Egalitarianism), expressed Bankim's intrepid censure of various kinds of social injustices and exploitation perpetuated by traditional Hindu society, his views against gender inequity and caste privileges were also unorthodox for his time. "Now the question before us is: is today's discrimination between a foreigner and a native worse than the traditional discrimination between the Brahman ad the Shudras?" (Summing Up Bankim). It seems that in Bankim there was the symbolic evolution of the culture of the Indian people as it witnessed the transition from the medieval to the modern age. To many scholars “the woman's question was a central issue in some of the most controversial debates over social 
reform in early and mid-nineteenth century Bengal- the period of the so called 'Renaissance'”' (Chatterjee, 1998, p. 240). And this manifested well in Bankim's fiction too. Bankim's Krishnakanta's Will (1878) and The Poisoned Tree (1884) were about widow remarriage, whereas the unfinished Rajmohan's Wife: A Novel serialized in 1864, documented the trials and tribulations of Matangini a volatile conglomeration of strength, energy and erotic power. She literally became an attractive figuration of the new Indian woman, who could risk all for her convictions. And Rajani has Bankim engaging with blindness as an experience felt by a lowly, poor girl vulnerable to manipulations by an indifferent and callous patriarchal and ableist society. "Disabled women struggle with both the oppressions of being women in male-dominated societies and the oppressions of being disabled in societies dominated by the ablebodied" (Wendell, 1989, p. 105).

At a time when there were slogans raised against the prevailing Hindu customs of "an infant widow passing her life in a state of celibacy, and the practice of polygamy and of widows burning" (Haldar, 1977, p. 40) in accordance with the sati pratha, was there enough awareness about the 'impaired' and 'disabled' woman in Bankim's society? The 'impaired' woman would suffer not just because of her impairment but doubly because of gender too. Was there the plausibility of ascribing rights to this liminal category of people living ironically as it was during the Bengal Renaissance said to be "wider, deeper, and more revolutionary than that of Europe after the fall of Constantinople"? (Mazumdar, 1960, p. 1). Who cared whether the 'handicapped' were leading a 'healthy' life or was it even possible for them to lead one? Was not the traditional definition of health 'the absence of disease or illness'? (Kronenfeld, 2002, p. 21). "This negative definition of health is often considered as a negative approach both because it is a limited definition and more importantly because it doesn't identify what health is, but only the negative of health" (ibid, p. 21). Rajani surely could not be considered a part of the 'healthy' population, productive and valuable, socially and economically. Censuses have often functioned to articulate the state's priorities and preconceptions and likewise the colonial census of the nineteenth century British India sought to classify and categorize and calculate the percentage of population rendered 'disabled'. Data on 'disabilities' or 'infirmities' as they were then termed were first registered in the 1872 census. "The colonial census offers the historian one of the richest sources on the experience of disability in general and blindness in particular" (Nair, 185). The disabled body was identified and rendered "non standard, deviant and undesirable" (Ibid, p. 185).

Bankim, through the character of Rajani, offered society the possibility of viewing the 'disabled' as possessing agency- Rajani narrates her own story, falls in love, desires a complete union of body, soul and spirit with her chosen man, helps the family in earning a respectable living, navigates with the aid of her cane the busy and treacherous streets of Calcutta. Mohit Kumar Ray on his observations on the character of Rajani writes, "Rajani does not indulge in self-pity. She asserts herself and claims to be equal with those who have eyes. She is as much assertive in defying her physical handicap as in declaring her love for Sacindra. ... Unlike Nydia, Rajani constantly asserts herself with unflinching determination, leaves her home, demonstrates her physical strength and capacity for self-defense by breaking a very hard stick and expresses her profound gratitude (not love) to Amarnath" (Ray, 2002, p. 175).

If there was a considerable body of knowledge generated on the socio-cultural inequities afflicting nineteenth century women in general, was there a similar awareness on the afflictions of women with 'disabilities'? Thus, Rajani whose tell-tale name meant 'night' and was named so to connote 'darkness', prods the conscience of the readers at the very outset. "Your lives are sighted- my life is dark- the problem is, I do not consider this life as dark" (Chattopadhaya, 1881, p. 1). It is a virtual reorientation of the prevailing ideas of helplessness and hopelessness associated with the 'disabled' that is undertaken by Bankim here. The subjective self of Rajani abhors to think of herself as flawed or incomplete rather it was the 'normal' society that stereotyped her and denied her a life of dignity, love and happiness. Her womb is of value only with herself otherwise obliterated by society.

Rajani is unfortunate more so as she is born in times that were marked by white rule and an inadequate indigenous understanding of various physical differences. Something as common as blindness can find a reference in the contemporary Bengali periodical literature only as a passing side effect of masturbation by boys. "... masturbation, through individual physical deterioration was seen ... as one of the main causes of India's backwardness... it had also led to a weakness in the power of arousal, paralysis, epilepsy, blindness, ... and many other kinds of diseases" (Bose, 2006, p. 34). What then would have been the kind of scientific awareness at that point of time regarding the causes of blindness and the socio-cultural limitations imposed on the blind? Rajani tries to draw the readers' attention to one 'difference" though that marks her from the 'normal'- she privileges the olfactory, the tactile senses over the sense of sight "I can get pleasure from the smell of a small flower whereas the full moon resplendent among all the stars will not make me happy"(Chatterjee, 1287, p. 1). In H. G. Well's The Country of the Blind (1904) an entire village having lost the faculty of sight generations ago is shown to have developed an entire 
culture adapted to sensory abilities. When a 'normal' human Nunez enters the village basking in the confidence of sight, he is humbled by the 'disabled' blind villagers- " 'His senses are still imperfect', said the third blind man.... 'He stumbles, and talks unmeaning words. Lead him by the hand' " (Esmail and Keep, 2009, p. 45).

Pradeep Kumar Bose in his book on nineteenth century society imagined through periodicals writes "... a look at the number and standard of the essays on health and medical practices will at once reveal that the speed with which these areas of knowledge flowered was much greater than others" (Bose, 2006, p. 11). This rising interest in health and medical practices stemmed from the scientific temper that the Britishers were said to have spread. The opening assumption in most of these discourses was however the "'weakness' and lack of strength of Indians especially Bengalis" (Ibid, 26). The essay entitled "The Revival of National Physical Health", pointed to the growing concern over "the deteriorating state of the physical health of Bengalis" (Ibid, p. 26). This palpable focus on the physical wellbeing of able-bodied Bengalis leaves everything unsaid, undiscoursed on the physical aspect of wellbeing of the 'infirm' population. Even if Rajani did not suffer from obvious physical limitations out of her blindness, she suffered psychological and social scarring which must have jeopardized her overall health.

Leading a 'normal' and socially fulfilling life was difficult for Rajani because of her congenital blindness. She claims out rightly "because I am blind, I couldn't get married" (Chattopadhyay, 1881, p. 3). This, in spite of the fact that she was young and beautiful. Various members of the society had bemoaned this loss to 'normal' society. Some had even wished for a different fate for themselves just to be able to marry the blind girl. "Wish I too had been blind" was a recurrent echo of many an aspiring suitor (Ibid, 3). This interiorization of the notion of worthlessness drives Rajani to solemnize her marriage on two different occasions to two different 'grooms'. At fifteen, she betroths herself to one of the gigantic, massive, all powerful, erect "monuments' that had sprung up in the bosom of Calcutta, busy developing as a massive centre of colonial trade, commerce and enterprise. The 'monument' became symbolic of the kind of groom that was desired by society then. Then at seventeen, Rajani, while engaged in playful banter with the Kayastha neighbor Kalicharan Basu's four-year-old son Bamacharan, proclaims the child to be her 'husband'. These two attempts by Rajani to fulfill by proxy one of the basic social duties of a human in society only goes on to highlight the prevailing social apathy, indifference and denial of roles to the 'blind'.

Later in the novel, the rich mistress of the household that Rajani visited, Lalitalabangalata, attempts to marry off Rajani to an already married Gopal, who agrees to wed only on the promise of a handsome dowry. Even Sacindra, the younger stepson of Lalitalabangalata, with whom Rajani is secretly in love, has strong reservations against marrying her because of her blindness. The support that Rajani could have garnered from her family is withdrawn as her parents can only think of performing the requisite duty of marrying off a daughter, even if that meant Gopal as the groom. The paternalising and condescending attitude of Lalitalabangalata towards Rajani was often the norm when the 'normal' tended to determine the desires, dreams, aspirations of the 'infirm'. Was the blind Rajani worthy of marrying only another blind? Was the blind Rajani worthy of marrying an already married man and only to provide him with an heir?

The sensibility of Rajani as a woman in love is the sensibility of a human being, nothing 'different' from the ordinary. Touched by Sacindra, who as a certified doctor was attempting to find the probability of a cure of her blindness, Rajani undergoes a sudden awakening of her desires, her sexuality. The feelings of love and desire are described beautifully in tactile, olfactory and auditory terms. She is not diffident and ashamed by the onslaught of emotions, passion and desire but only realizes how the society would not accept or rather could not fathom the similarity between her and any other 'normal' girl.

There were occasions when Rajani had to live with the fact of charity and pity that 'normal' society automatically offered to her because of her blindness. Lalitalabangalata for instance would pay her an inflated amount of money as payment for the garlands that Rajani would bring to sell to her. Instead of the four anas Rajani would be given two rupees every day. This generosity on the part of Lalitalabangalata didn't go unacknowledged by Rajani, who tells the readers that it practically sustained their household, otherwise living purely on the basis of selling flowers. Rajani's blindness, her lowly background and her gender were causes of humiliation on a daily basis. As a blind and poor girl, she would be placed at the bottom of all social considerations and hierarchy. The literary character on which Bankim had modelled Rajani, Nydia, ultimately fails to withstand social apathy and exploitation, and commits suicide. Our Rajani till the end engages in a dignified assault on the assumptions of society and works to maintain her selfhood.

The British poor law system operative in England in the nineteenth century was designed to provide care and sustenance to the blinds in particular and disabled people in general. The workhouses as designated for them was nothing but "a prison like place where conditions were purposely made so bad that they encouraged people to starve rather than live there" (Lacom, 2005, p. 547). There, various distinctions were made between "able-bodied poor", 
"impotent poor", the "infirm poor", and the "aged poor" (Ibid, p. 547). At the time of the writing of Rajani such poor houses were probably non-existent in India with the reference emerging only in the twentieth century colonial archive. It was the family or the community, which would extend help and support when it came to 'infirms' in the Indian context.

"The health of European soldiers, whether in the service of the British army or, until 1858, in the company's own European regiments, was one of the primary responsibilities of the medical profession" (Arnold, 1985, p. 167). Later on too, the colonial health system was engaged in "ministering to the health of Europeans in India" (Ibid, p. 168). If anyone perceived Rajani's Calcutta in reality, it would have emerged to have undergone a demarcation of sorts, separating the white areas from the native zones - "in the southern part live the English. In this part, the houses are beautiful and clean. There are broad and clean roads. On the other hand, is the north, where the native people live- there this kind of environment does not exist" (Bose, 2006, p. 39). Literature on the health and society of nineteenth century Bengal have subsequently established how "the English created areas like Cantonments, Civil Lines, hill stations and so on with the aim of preserving health" (ibid, p. 39). We herein notice how topography contributed to the reinforcement of the image of the whites as distinctly different and superior than the natives. The whites had similarly sought to employ the strategy of spatial demarcation through the construction of black townships in apartheid South Africa to separate the races and ensure minimal contact.

If at all there were discourses on health issues of the natives in the late nineteenth century Bengal, they centered on public health, pertaining to epidemics like cholera, kala-azar, smallpox etc. David Arnold likewise writes, "Until the 1860s and 1870s, western medicine knew correspondingly little about the health of the majority of the Indian populations, particularly about non-epidemic disease" (Arnold, 1985, p. 170). Impairment however defined and acquired, however critical, was rarely present in the colonial agenda as well as in the indigenous health and medical literature of the nineteenth century. The medical gaze, either of the scientific man or the superstitious perhaps didn't sufficiently consider falling on a liminal category of population that survived merely as parasites.

It is then surprising to find in the fiction of Bankim and Tagore some stray depictions of disability arising out of impairment. In Rajani it is the heroine's gradual emancipation from all physical, psychological, economic restraints that invest novelty but we are left with the feeling that such a happy turn of events could only be a figment of the novelist's imagination. Such literary resonances were not yet to be found or located in real society. Stigma was attached with blindness as Census enumerators noted how there were families who attempted to conceal "blindness among young unmarried female members of the household; suggesting that there was certainly some social under ability ascribed to blindness" (Nair, 2017, p. 190). But it was also acknowledged how blind women were hardly "ever allowed by their families to lapse into mendicancy...." (Ibid, p. 191).

The main interest of Bankim in Rajani doesn't seem to be to provide a scientific, rational understanding of blindness, its causes and cures. Bankim's proclamations while discussing the debate between ancient Shastras and modern science " but if you really insist on a choice, then it is science I accept. Because, if you do not accept science theses days people will call you an idiot. If you accept the scientific principles, people say this man knows English. That is a credit I cannot forsake. And if you accept science, you ca escape from the restrictions imposed by Hinduism with the minimum of effort. That is no small comfort. So, it is science that I shall follow" (Bose, 2006, p. 32) - fail to explain how Rajani, suffering from congenital blindness, is suddenly cured. We do remember how, quite early in the novel, Sacindra babu as an established and respectable medical practitioner had negated the possibility of Rajani ever gaining sight. Bankim has Rajani regaining her vision not through scientific interventions but through the grace of an ascetic, something that science could not have predicted or ensured. In spite of Bankim's proclamation of rational and scientific postulates, we encounter this incongruity.

\section{Conclusion}

According to many, Rajani is Bankim's experiment with what came to be known later as the psychological type of fiction and surely enough Rajani's blindness and poor economic status and the reversals, reveal the dynamics of the psychological framework of many a character in the story. As we read Bankim anew in the twenty-first century, we find in Rajani the plausibility of a reading from Disability Studies perspective even if we fault Bankim for providing a fairy tale ending to Rajani's trials and tribulations. Bankim does provide posterity an early glimpse into the impact of visual impairment and disability on human health. Rajani emerges to be Bankim's subtle critique of a society that knew to privilege only perfection. 


\section{SOURCES OF FUNDING}

None.

\section{CONFLICT OF INTEREST}

None.

\section{ACKNOWLEDGMENT}

None.

\section{REFERENCES}

[1] Bose, Pradip Kumar. (Ed.). Ed. Health and Society in Bengal: A Selection from Late 19th Century Bengali Periodicals. New Delhi: Sage; 2006.

[2] Chattopadhyay, Bankim Chandra. (Bengali year 1287, English 1881). Rajani. Katalpara: Radhanath Bandopadhyay Press. 1881.

[3] Chatterjee, Partha. (1998). The Nation and its Women. In Ranajit Guha (Ed.), A Subaltern Studies Reader. New Delhi: OUP.

[4] David, Arnold. (1985). Medical Priorities and Practice in Nineteenth-Century British India. South Asia Research. Vol. 5, No.2. pp. 167-183.

[5] Esmail, Jennifer and Christopher Keep. (2009). Victorian Disability: Introduction. Victorian Review. Vol. 35, No. 2. pp. 45-51.

[6] Haldar, M. K. (1977). Renaissance and Reaction in Nineteenth Century Bengal. Calcutta: Minerva Associates (Publications) Pvt. Ltd.

[7] Kronenfeld, J. J. (2002). Health Care Policy: Issues and Trends. London: Praeger.

[8] Lacom, Cindy. (2005). "The Time is Sick and out of Joint": Physical Disability in Victorian England. PMLA. Vol. 120, No.2. pp. 547-552.

[9] Majumdar, R.C. (1960). Glimpses of Bengal in the Nineteenth century. Calcutta: Firma K L Mukhopadhyay Agents.

[10] Nair, Aparna. (2017). 'They Shall See His Face': Blindness in British India, 1850-1950. Med. Hist. Vol. 61 (2). pp. 181-199.

[11] Ray, Mohit Kumar. (2002). Studies in Literary Criticism. New Delhi: Atlantic Publishers.

[12] Wendell, Susan. (1997). Toward a Feminist Theory of Disability. Hypatia. Vol. 4, No. 2. pp. 104-124.

[13] Summing up. (n. d.). In The Book Review Trust. Retrieved June 11, from https://www.thebookreviewindia.org/summing-up-bankim/ 